\title{
Potential for Phytoremediation of PCDD/PCDF-Contaminated Sludge and Sediments Using Cucurbitaceae Plants: A Pilot Study
}

\author{
Magdalena Urbaniak ${ }^{1,2}$ - Anna Wyrwicka ${ }^{3}$ Marek Zieliński ${ }^{4}$. \\ Joanna Mankiewicz-Boczek ${ }^{1,2}$
}

Received: 21 January 2016/ Accepted: 23 June 2016/Published online: 30 June 2016

(C) The Author(s) 2016. This article is published with open access at Springerlink.com

\begin{abstract}
The current study evaluates the impact of sewage sludge and urban reservoir sediment on changes in total and Toxic Equivalency (TEQ) PCDD/PCDF concentration in soil and phytotoxicity measured using three test species: Lepidium sativum, Sinapis alba, and Sorghum saccharatum, during 5 weeks of Cucurbita pepo L. cv 'Atena Polka' (zucchini) cultivation. 'Atena Polka' was found to reduce total PCDD/ PCDF concentration by $37 \%$ in soil amended with sludge and $32 \%$ in soil treated with sediment from an urban reservoir. The TEQ reduction was almost twofold greater: $68 \%$ in soil amended with sludge and $52 \%$ with urban sediment. Addition of sludge increased root growth inhibition of $L$. sativum, S. alba and S. saccharatum, from $44 \%$ to $90 \%$. Observed inhibitions were, however, reduced by 'Atena Polka' cultivation, and as high as $32 \%$ promotion in root length was noted. Amendment with urban sediment, in turn, resulted in an initial 1\%-36\% promotion of root growth, while 'Atena Polka' cultivation reduced this positive effect by inhibition as
\end{abstract}

Electronic supplementary material The online version of this article (doi:10.1007/s00128-016-1868-6) contains supplementary material, which is available to authorized users.

Magdalena Urbaniak

m.urbaniak@unesco.lodz.pl

1 European Regional Centre for Ecohydrology of the Polish Academy of Sciences, Tylna 3, 90-364 Lodz, Poland

2 Department of Applied Ecology, Faculty of Biology and Environmental Protection, University of Lodz, Banacha 12/16, 90-237 Lodz, Poland

3 Department of Plant Physiology and Biochemistry, Faculty of Biology and Environmental Protection, University of Lodz, Banacha 12/16, 90-237 Lodz, Poland

4 Nofer Institute of Occupational Medicine, Teresy 8, 91-348 Lodz, Poland high as $26 \%$. Results demonstrated positive influence of 'Atena Polka' on the phytotoxicity alleviation and mitigation of total and TEQ PCDD/PCDF concentrations in soil treated with bio-solids from sewage sludge and an urban reservoir.

Keywords Sewage sludge · Urban sediments · Phytotoxicity $\cdot$ Phytoremediation

Production of sewage sludge is steadily increasing, and the question of its safe and responsible disposal is gaining importance. Similarly, sediments accumulated in small urban water bodies need to be periodically dredged to avoid reservoir siltation, while also utilizing them in a safe way due to impurities they contain, such as polychlorinated dibenzo-p-dioxins (PCDDs) and polychlorinated dibenzofurans (PCDFs), whose storage and utilization represent a risk for the environment.

Most PCDDs and PCDFs are characterized by high hydrophobicity, expressed by their high $\log \mathrm{K}_{\mathrm{ow}}$ value. Studies have shown substances with a $\log \mathrm{K}_{\mathrm{ow}}>3.5$ are not bioavailable to plants, since they are strongly adsorbed by soil particles and do not pass into the soil solution from which they could be taken up (Briggs et al. 1982). By comparison, toxic congeners of $\mathrm{PCDD} / \mathrm{PCDF}$ are characterized by $\log \mathrm{K}_{\mathrm{ow}}$ values ranging from 6.53 to 8.78 . Studies have reported vegetables (Lovett et al. 1997), fruits (Müller et al. 1993), rice (Ugeaki et al. 2006) and grasses and weeds (Reischl et al. 1989) are unable to phytoextract, transport and accumulate PCDDs/PCDFs in their tissues.

Exceptions to this are plants of the Cucurbitaceae family, which are able to take up PCDDs/PCDFs, as well as other POPs such as PCBs, from the soil and translocate them to stems and leaves (Wyrwicka et al. 2014; Greenwood et al. 2011; Low et al. 2011; Low and Whitfield 
Aslund 2010; Inui et al. 2008; Engwall and Hjelm 2000; Hülster et al. 1994). However, as considerable differences have been observed to date between the uptake and translocation of selected POPs, the correct selection of an appropriate Cucurbitaceae species/cultivar is an important consideration in maximizing phytoremediation efficiency (Inui et al. 2008). This is important in bio-solid amended soils, which contain a vast array of organic and inorganic compounds with varied properties and toxicity.

The aim of this study was to evaluate the suitability of the most common Cucurbita pepo L. cultivar in PolandC. pepo L. cv 'Atena Polka' (zucchini)—as a phytoremediation tool for soil contaminated with PCDDs/PCDFs from sewage sludge and urban reservoir sediment. The impact of sewage sludge and urban reservoir sediment on changes in soil toxicity and phytotoxicity were measured before and after 5 weeks of $C$. pepo L. cv 'Atena Polka' cultivation, the former measured as total and Toxic Equivalency (TEQ) PCDD/PCDF concentration, and the latter using three test species: Sinapis alba L., Lepidium sativum L. and Sorghum saccharatum (L.) Moench.

\section{Materials and Methods}

Sewage sludge from the Lodz Municipal Wastewater Treatment Plant and urban sediments from the sedimentation pond constructed on the Sokołówka River in Lodz (Central Poland) were collected and used as soil additives (Wyrwicka et al. 2014). Sewage sludge and sediments were dried at $70^{\circ} \mathrm{C}$ for $72 \mathrm{~h}$, homogenized into small particles using a mortar, and then used as an additive for the vegetable potting soil. Vegetable potting soil (specified for Cucurbitaceae growth) used in the experiment was collected from Hollas Sp. z o.o. Pasłęk.

Three study groups with $1.8,5.4$ or $10.8 \mathrm{~g}$ sewage sludge/urban sediment per $300 \mathrm{~mL}$ flower pot were used, as well as a control in which no sludge or urban sediment was added. Each treatment variant was prepared in three replicates. Doses used constituted $1.5,4$ and $8 \%$ of the total dry weight of sample. The $1.8 \mathrm{~g}$ treatment corresponded to a dose of 3 tonnes per hectare (t/ha), the permitted annual dosage of municipal sewage sludge by the Ministry of the Environment Regulations (Journal of Laws 2015 , item 257) while $5.4 \mathrm{~g}$ represented the permitted dose of $9 \mathrm{t} / \mathrm{ha}$ applied on one occasion per 3 years. The above permissible doses of sludge, despite effectively protecting the soil environment against pollution (e.g. by metals), largely limit the possibilities of enriching soil organic matter and thus increasing soil fertility. Therefore to assess the impact of high amounts of sludge and sediments on soil pollution measured as PCDDs/PCDFs and its phytotoxicity, the study also used a dose of $10.8 \mathrm{~g}$, which corresponds to $18 \mathrm{t} / \mathrm{h}$, thus significantly exceeding the permitted level. Physico-chemical properties of used soil and soil amended with $9 \mathrm{t} / \mathrm{ha}$ of each additive are depicted in Table 1S.

Cucurbita pepo L. cv 'Atena Polka' seeds were germinated in Petri dishes for 7 days. Seedlings were planted in the control and sewage sludge- or sediment-amended soil samples and then cultivated for a 5-week period in a growth chamber at $23^{\circ} \mathrm{C}\left( \pm 0.5^{\circ} \mathrm{C}\right)$ with $16 \mathrm{~h}$ light/ $8 \mathrm{~h}$ dark cycle and $150 \mathrm{mmol} \mathrm{m}^{-2} \mathrm{~s}^{-1}$ photon flux density during the light period, with $60 \%$ relative humidity.

Analysis of the 17 toxic congeners of PCDD/PCDF was performed according to PN-EN 1948-2(2002) and US EPA Method 1613 (1994) using the isotope dilution method and 6890 N High Resolution Gas Chromatography/High Resolution Mass Spectrometry system (Agilent Technologies) with a DB-5MS column (Urbaniak et al. 2014). Final results were expressed as the TEQ of each sample, operationally defined by the sum of the concentrations of each congener in the mixture multiplied by its Toxic Equivalency Factor (TEF) (Van den Berg et al. 2006). All analytical work was performed in the Laboratory of Environmental Biochemistry at the Nofer Institute of Occupational Medicine, Lodz, Poland. Quantification was performed using certified calibration standards. Each analytical batch contained a sample blank, control sample, certified reference material and in-house control material. Analyte recoveries were determined by analyzing samples spiked with PCDD/PCDF standards. A reagent blank was used to assess artifacts, the precision was verified by duplicate analyses, and recoveries were estimated using samples spiked with PCDD/PCDF. Sample spikes were used to further confirm accuracy. LOD values obtained through the analytical procedure ranged from 0.068 to $0.137 \mathrm{ng} / \mathrm{kg}$ for PCDDs and 0.053 to $0.143 \mathrm{ng} / \mathrm{kg}$ for PCDFs.

The Phytotoxkit ${ }^{\mathrm{TM}}$ test kit (Microbiotests inc, Belgium) was used to assess phytotoxicity of soil before and after $C$. pepo L. cv 'Atena Polka' cultivation. Three test plant species were used: the monocotyledon S. saccharatum (L.) Moench and the dicotyledons L. sativum (L.) and S. alba (L.). Response of test species was classified as toxic when the percentage effect of root growth inhibition $\geq 20 \%$ (Persoone et al. 2003).

All results were subjected to statistical analyses using Statistica software for Windows. The Wilcoxon matchedpair test was used to compare changes in total and TEQ concentrations, as well as soil sample phytotoxicity, before and after C. pepo L. cv 'Atena Polka' cultivation.

\section{Results and Discussion}

Plants have been frequently shown to remove POPs from soils (Zhao et al. 2006; Susarla et al. 2002; Macek et al. 2000). The high propensity of selected Cucurbitaceae to 
extract PCDDs/PCDFs from soil was first reported by Hülster et al. (1994), who found that $C$. pepo L. fruits contained double the PCDD/PCDF concentrations of other examined plants. Zhang et al. (2009) reported that $C$. pepo L. roots effectively enable the uptake and subsequent translocation of PCDDs/PCDFs to aboveground parts. Inui et al. (2008) found the C. pepo cv 'Patty Green', 'Gold Rush' and 'Black Beauty' to have varied PCDD/PCDF phytoextraction capacities. Although aerial parts of 'Patty Green' demonstrated TEQ levels twice those found in tobacco plants, 'Black Beauty' and 'Gold Rush' demonstrated TEQ levels 180-fold higher than those of Patty Green. These studies were based mostly on the PCDD/ PCDF concentrations in plant tissue (roots, leaves, fruits) and did not exhibit their changes in soil due to C. pepo $\mathrm{L}$. cultivation. Moreover, available literature data concerning removal of PCDDs/PCDFs by $C$. pepo L. monitored mostly changes of single congener or group of congeners over time (Zhang et al. 2009; Campanella and Paul 2000; Hülster and Marschner 1994). The present study assessed the efficacy of $C$. pepo L. as a phytoremediation tool for soil contaminated due to application of bio-solids - a mixture of different compounds with varied properties and toxicity.

Current results demonstrated that cultivation of $C$. pepo L. cv. 'Atena Polka' reduced total PCDD/PCDF content by a mean value of $37 \%$ in soil amended with sewage sludge and $32 \%$ in soil treated with urban sediment (Fig. 1A1, B1; Table 2S). Mean reduction in TEQ concentrations were 68 and $52 \%$ in soil amended with sewage sludge and sediment, respectively; values almost twice those of PCDD/PCDF content (Fig. 1A2, B2; Table 2S). Wilcoxon matched pair test revealed significant differences in total and TEQ values before and after $C$. pepo L. cv. 'Atena Polka' cultivation at $p=0.067$. The greatest decline of total PCDD/PCDF content was observed for control samples (66\% for soil with sewage sludge and $81 \%$ for soil with sediment), while the greatest reduction of TEQ values was detected in samples fertilized with 9 and $18 \mathrm{t} / \mathrm{ha}$ of sewage sludge (72 and $73 \%$, respectively) (Fig. 1; Table 2S). In soil amended with 3 t/ha of sludge, 'Atena Polka' cultivation led to a $63 \%$ reduction of TEQ. Other large decreases were also noted for soil amended with 9 and $18 \mathrm{t} / \mathrm{ha}$ of urban sediments (59 and $70 \%$, respectively), while a much smaller reduction (21\%) was noted for a dose of $3 \mathrm{t} / \mathrm{ha}$ (Fig. 1; Table 2S). The above declines in soil total and TEQ PCDD/PCDF concentrations are, from one site, a result of 'Atena Polka' cultivation, however, the bioremediation activity of soil microorganisms seems to also be an important factor responsible for the obtained reductions (Urbaniak 2013; Field and Sierra-Alvarez 2008).
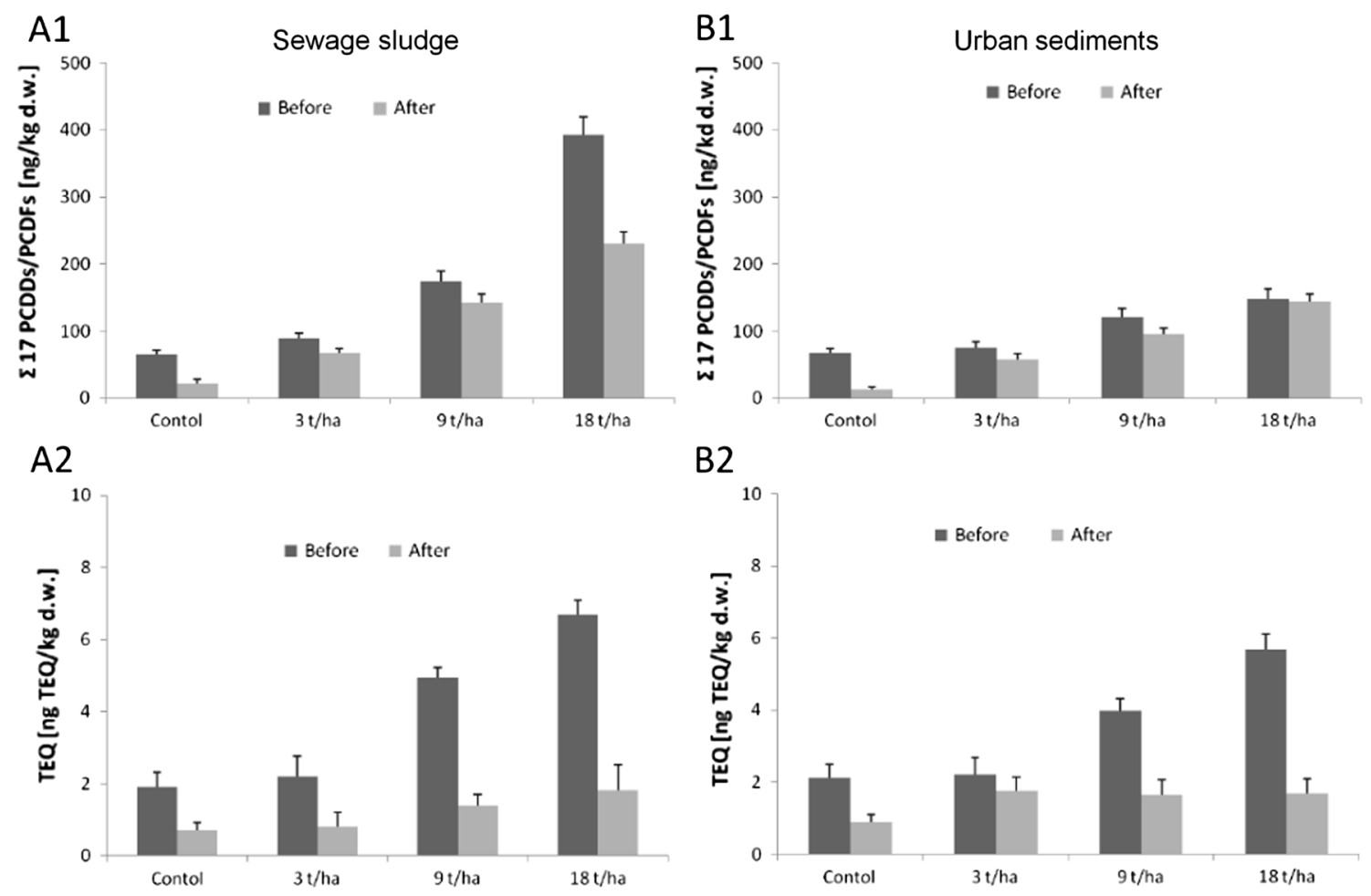

Fig. 1 Mean decreases in total and TEQ PCDD/PCDF concentrations in soil amended with different doses of sewage sludge (A1, A2) and urban sediments (B1-B2) before and after Cucurbita pepo L. cv 'Atena Polka' cultivation 

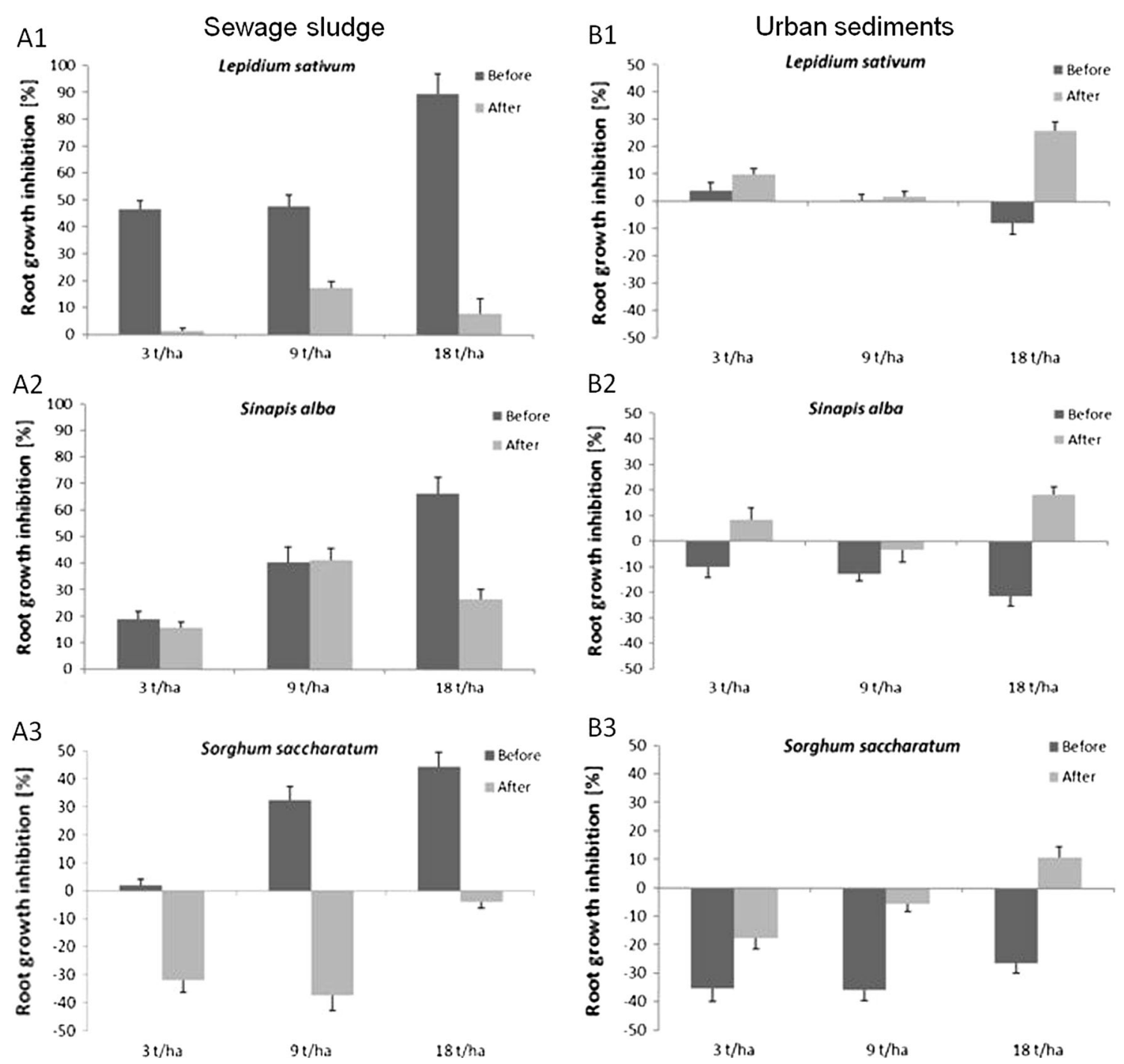

Fig. 2 Mean effect of different doses of sewage sludge (A1-A3) and urban sediments (B1-B3) on root growth inhibition before and after Cucurbita pepo L. cv 'Atena Polka' cultivation (negative values indicated increase in the root growth in comparison to the control soil)

The study also showed that, while observed declines in TEQ reduction were found to be irrespective of sewage sludge concentration $(63,72$ and $73 \%$ for 3,9 and $18 \mathrm{t} / \mathrm{ha}$, respectively) (Fig. 1A2; Table 2S), for samples amended with urban sediments, removal efficiency significantly increased $(p=0.067)$ together with sediment dose $(21,59$ and $70 \%$ for 3,9 and $18 \mathrm{t} / \mathrm{ha}$, respectively) (Fig. 1B2; Table $2 \mathrm{~S}$ ). Greater differences in reduction rates were observed between samples treated with lower doses of sludge and sediment: 42,13 and $3 \%$ differences for 3, 9 and $18 \mathrm{t} / \mathrm{ha}$, respectively (Fig. 1A2, B2; Table 2S). Similarly Wyrwicka et al. (2014) reported that the use of $\mathrm{Cu}$ cumis sativus L. led to a greater reduction of PCBs in samples treated with sewage sludge than those treated with urban sediment, and similar increases in PCB reduction were found with increasing sediment treatment.
'Atena Polka' was also found to play a positive role on changes in soil phytotoxicity. Although high root growth inhibition was initially observed for $S$. saccharatum (44\%), S. alba (66\%) and L. sativum $(90 \%)$ in soil treated with $18 \mathrm{t} /$ ha sewage sludge (Fig. 2A1-A3), these values decreased after 'Atena Polka' cultivation: $26 \%$ in the case of $S$. alba (Fig. 2A2), $8 \%$ for $L$. sativum and $4 \%$ for $S$. saccharatum. A similar situation was observed for lower doses of sludge. The greatest inhibition of root growth was observed for L. sativum: $46 \%$ (3t/ha) and $47 \%$ (9 t/ha) before 'Atena Polka' cultivation, falling to $1 \%(3 \mathrm{t} / \mathrm{ha})$ and $17 \%(9 \mathrm{t} / \mathrm{ha})$ after 5 weeks of plant cultivation (Fig. 2A1). Much greater alleviation of soil toxicity was demonstrated by $S$. saccharatum, with a $32 \%$ increase in root growth observed at $3 \mathrm{t} / \mathrm{ha}$ and $27 \%$ for $9 \mathrm{t} /$ ha (Fig. 2A3), while S. alba demonstrated the lowest 
reduction in soil toxicity (Fig. 2A2). No significant differences in soil phytotoxicity before and after 'Atena Polka' cultivation $(p=0.109)$ were noted.

Opposite results were observed for samples amended with urban sediments. No toxic effects were observed, as all test species showed an increase in root growth, with the greatest being observed for $S$. sacharatum (36\%) (Fig. 2B1-B3). However, this positive effect diminished after application of 'Atena Polka', with root growth inhibition as high as $26 \%$ (Fig. 2B1-B3).

Results indicate that while applied sewage sludge negatively affected growth of all test plants, the degree of inhibition depended on the plant type. The greatest tolerance to sewage sludge was shown by $S$. saccharatum and the lowest by $L$. sativum. Similar results, with the high resistance of $S$. saccharatum and sensitivity of $L$. sativum to sludge application, were obtained in the study by Oleszczuk and Hollert (2011). High sensitivity of $L$. sativum has also been confirmed in other studies worldwide (Oleszczuk et al. 2012; Ramirez et al. 2008; Alvarenga et al. 2007). Such high phytotoxicity could possibly be due to the composition of the amendment, as sewage sludge contains a range of pollutants other than PCDDs/PCDFs, such as PCBs (Wyrwicka et al. 2014) and metals, which usually exceed the allowed doses (Journal of Laws 2015, item 257) and can negatively affect the condition of the soil and the plant. Urban sediments, in turn, are rich in phosphorus, iron and calcium which are valuable for arable farming and the reconditioning of sandy and degraded soils, while metals remain low (see Table 1S). Urban sediments alleviate toxic effects of PCDDs/PCDFs and other pollutants, which manifest themselves in increased $L$. sativum, S. alba and S. saccharatum root growth. Further decreases observed in the positive effects of sediment treatment associated with 'Atena Polka' cultivation can be related to soil impoverishment.

With regard to the mitigation of soil phytotoxicity as an effect of $C$. pepo cultivation, the highest average reduction was demonstrated by S. saccharatum (59\%) and L. sativum (52\%), while $S$. alba showed the lowest average decline (14\%). Obtained differences may be related to the sensitivity of test plants to soil pollution. While C. pepo is effective for the removal of organic compounds, it is not sufficient to remove metals. The high inhibition of $S$. alba roots observed following $C$. pepo cultivation may be related to the mix of pollutants remaining in soil after the phytoremediation process. Baran and Tarnawski (2015) reported $S$. alba to be particularly sensitive to metals, while Steliga et al. (2012) noted that it is not susceptible to soil organic contaminants.

Results demonstrate that cultivation of 'Atena Polka' plays a positive role in reducing total PCDD/PCDF soil concentration and TEQ equivalent, with the highest reduction efficiency observed in soil treated with sewage sludge. Administration of sludge was found to result also in high inhibition of root growth by the test plants $L$. sativum, $S$. alba and S. saccharatum, while the application of 'Atena Polka' alleviated the negative effects of sludge usage. Opposite results were obtained for soil amended with urban sediments, which demonstrated not only lower total PCDD/ PCDF concentrations and hence, lower efficiency in their removal, but also a lack of toxic response of $L$. sativum, $S$. $a l b a$ and $S$. saccharatum. Results demonstrated the positive influence of 'Atena Polka' on phytotoxicity alleviation and mitigation risk related to PCDDs/PCDFs in soil treated with bio-solids. Results confirmed potential of the used cultivar in remediation of soils contaminated with biosolids containing a mixture of different compounds with varied properties and toxicity.

Acknowledgments Scientific work funded under the Ministry of Science and Higher Education programme under the name "Iuventus Plus" for the years 2015-2017: Project No. IP2014 049273, and the project funded by the National Science Centre granted on the basis of the decision number DEC-2013/09/D/ST10/04043.

Open Access This article is distributed under the terms of the Creative Commons Attribution 4.0 International License (http://crea tivecommons.org/licenses/by/4.0/), which permits unrestricted use, distribution, and reproduction in any medium, provided you give appropriate credit to the original author(s) and the source, provide a link to the Creative Commons license, and indicate if changes were made.

\section{References}

Alvarenga P, Palma P, Goncalves AP, Fernandes RM, Cunha-Queda AC, Duarte E, Vallini G (2007) Evaluation of chemical and ecotoxicological characteristics of biodegradable organic residues for application to agricultural land. Environ Int 33:505-513

Baran A, Tarnawski M (2015) Assessment of heavy metals mobility and toxicity in contaminated sediments by sequential extraction and a battery of bioassays. Ecotoxicology 24:1279-1293

Briggs GG, Bromilow RH, Evans AA (1982) Relationships between lipophilicity and root uptake and translocation of non-ionized chemicals by barley. Pestic Sci 13:495-504

Campanella B, Paul R (2000) Presence in the rhizosphere and leaf extracts of zucchini (Cucurbita pepo L) and melon (Cucumis melo L.) of molecules capable of increasing the apparent aqueous solubility of hydrophobic pollutants. Int $\mathrm{J}$ Phytorem 2(2):145-158

Engwall M, Hjelm K (2000) Uptake of dioxin-like compounds from sewage sludge into various plant species-assessment of levels using a sensitive bioassay. Chemosphere 40:1189-1195

Field JA, Sierra-Alvarez R (2008) Microbial degradation of chlorinated dioxins. Chemosphere 71:1005-1018

Greenwood SJ, Rutter A, Zeeb BA (2011) The absorption and translocation of polychlorinated biphenyl congeners by Cucurbita pepo ssp pepo. Environ Sci Technol 45:6511-6516

Hülster A, Marschner H (1994) The influence of root exudates on the uptake of PCDD/PCDF by plants. Organohalogen Comp $20: 31-34$ 
Hülster A, Müller JF, Marschner H (1994) Soil-plant transfer of polychlorinated dibenzo- $p$-dioxins and dibenzofurans to vegetables of the cucumber family (Cucurbitaceae). Environ Sci Technol 28:1110-1115

Inui H, Wakai T, Gion K, Kim YS, Eun H (2008) Differential uptake for dioxin-like compounds by zucchini subspecies. Chemosphere 73:1602-1607

Journal of Laws (2015) Regulation of the Minister of Environment dated 6 February 2015 on municipal sewage sludge

Lovett AA, Foxall CD, Creaser CS, Chewe D (1997) PCB and PCDD/ $\mathrm{DF}$ congeners in locally grown fruit and vegetable samples in Wales and England. Chemosphere 34:1421-1436

Low JE, Whitfield Aslund ML (2010) Effect of plant age on PCB accumulation by Cucurbita pepo ssp. pepo. J Environ Qual 39:245-250

Low JE, Whitfield Aslund ML, Rutter A, Zeeb BA (2011) The effects of pruning and nodal adventitious roots on polychlorinated biphenyl uptake by Cucurbita pepo grown in field conditions. Environ Pollut 159:769-775

Macek T, Mackova M, Kas J (2000) Exploitation of plants for the removal of organics in environmental remediation. Biotechnol Adv 18:23-34

Müller JF, Hülster A, Papke O, Ball M, Marschner H (1993) Transfer pathways of PCDD/PCDF to fruits. Chemosphere 27:195-201

Oleszczuk P, Hollert H (2011) Comparison of sewage sludge toxicity to plants and invertebrates in three different soils. Chemosphere 83(4):502-509

Oleszczuk P, Malara A, Jośko I, Lesiuk A (2012) The phytotoxicity changes of sewage sludge-amended soils. Water Air Soil Pollut 223(8):4937-4948

Persoone G, Marsalek B, Blinova I, Torokne A, Zarina D, Manusadzianas L, Nałęcz-Jawecki G, Tofan L, Stepanova N, Tothova L, Kolar B (2003) A practical and user-friendly toxicity classification system with microbiotest for natural waters and wastewaters. Environ Toxicol 18(6):395-402

PN-EN 1948-2 (2002) Emission from stationary sources. Determination of PCDD/PCDF mass concentration. PRT 3: Identification and quantification (in Polish)

Ramirez WA, Domene X, Andreas P, Alcanitz JM (2008) Phytotoxic effects of sewage sludge extracts on the germination of three plant species. Ecotoxicology 17:834-844
Reischl A, Reissinger HT, Hutzinger O (1989) Uptake and accumulation of $\mathrm{PCDD} / \mathrm{F}$ in terrestrial plants: basic considerations. Chemosphere 19:467-474

Steliga T, Jakubowicz P, Kapusta P (2012) Changes in toxicity during in situ bioremediation of weathered grill waste contaminated with petroleum hydrocarbons. Biores Technol 125:1-10

Susarla S, Medina VF, McCutcheon SC (2002) Phytoremediation: an ecological solution to organic chemical contamination. Ecol Eng 18:647-658

Ugeaki R, Seike N, Otani T (2006) Polychlorinated dibenzo- $p$ dioxins, dibenzofurans, and dioxin-like polychlorinated biphenyls in rice plants: possible contaminated pathways. Chemosphere 65:1537-1543

Urbaniak M (2013) Biodegradation of PCDD/PCDF and dl- PCB. In: Chamy R, Rosenkran F (eds) Biodegradation-engineering and technology. INTECH Publisher. pp 73-100, ISBN 978-953-511153-5

Urbaniak M, Kiedrzyńska E, Zieliński M, Tołoczko W, Zalewski M (2014) Spatial distribution and reduction of PCDD/PCDF toxic equivalents along the three shallow lowland reservoirs. Environ Sci Pollut Res 21:4441-4452

US EPA Method 1613, Revision B (1994) Tetra through octa chlorinated dioxins and furans by isotope dilution HRGC/ HRMS, US EPA

Van den Berg M, Birnbaum LS, Denison M, De Vito M, Farland W et al (2006) The 2005 World Health Organization reevaluation of human and mammalian toxic equivalency factors for dioxins and dioxin-like compounds. Toxicol Sci 93(2):223-241

Wyrwicka A, Steffani S, Urbaniak M (2014) The effect of PCBcontaminated sewage sludge and sediment on metabolizm of cucumber plants (Cucumis sativus L.). Ecohyd Hydrobiol 14:75-82

Zhang H, Chen J, Ni Y, Zhang Q, Liang Z (2009) Uptake by roots and translocation to shoots of polychlorinated dibenzo- $p$-dioxins and dibenzofurans in typical crop plants. Chemosphere 76:740-746

Zhao X, Zheng M, Zhang B, Zhang Q, Liu W (2006) Evidence for the transfer of polychlorinated biphenyls, polychlorinated dibenzo$p$-dioxins, and polychlorinated dibenzofurans from soil into biota. Sci Total Environ 368:744-752 